\title{
Interaction of Iron(III)-5,10,15,20-Tetrakis (4-Sulfonatophenyl) Porphyrin with Chloroquine, Quinine and Quinidine
}

\author{
Dikima D. Bibelayi1, Pitchouna I. Kilunga1, Albert S. Lundemba1, Matthieu K. Bokolo', \\ Pius T. Mpiana1, Philippe V. Tsalu2*, Juliette Pradon³, Colin C. Groom ${ }^{3}$, Celine W. Kadima4, \\ Luc Van Meervelt ${ }^{5}$, Zephyrin G. Yav ${ }^{*}$
}

\author{
${ }^{1}$ Department of Chemistry, University of Kinshasa, Kinshasa, Democratic Republic of Congo \\ ${ }^{2}$ Department of Chemistry, University of Ulsan, Ulsan, Republic of Korea \\ ${ }^{3}$ The Cambridge Crystallographic Data Centre, Cambridge, UK \\ ${ }^{4}$ Department of Chemistry, State University of New York at Oswego, Oswego, USA \\ ${ }^{5}$ Department of Chemistry, Katholieke Universiteit Leuven, Leuven, Belgium \\ Email: * philippetsalu.@yahoo.fr, ${ }^{\star}$ zgyav@yahoo.fr
}

How to cite this paper: Bibelayi, D.D., Kilunga, P.I., Lundemba, A.S., Bokolo, M.K., Mpiana, P.T., Tsalu, P.V., Pradon, J., Groom, C.C., Kadima, C.W., Van Meervelt, L. and Yav, Z.G. (2017) Interaction of Iron(III)-5, 10,15,20-Tetrakis(4-Sulfonatophenyl) Porphyrin with Chloroquine, Quinine and Quinidine. Crystal Structure Theory and Applications, 6, 25-38.

https://doi.org/10.4236/csta.2017.63003

Received: June 1, 2017

Accepted: August 8, 2017

Published: August 11, 2017

Copyright $\odot 2017$ by authors and Scientific Research Publishing Inc. This work is licensed under the Creative Commons Attribution International License (CC BY 4.0).

http://creativecommons.org/licenses/by/4.0/ (c) (i) Open Access

\begin{abstract}
Iron(III)-5,10,15,20-tetrakis(4-sulfonatophenyl) porphyrin (FeTPPS) is used as non-physiological metalloporphyrin model for the natural iron (III)-protoporphyrin IX (FePPIX) resulting from hemoglobin degradation to investigate ligand binding reactions in aqueous solution. Studies were conducted on the interaction of FeTPPS with Chloroquine, Quinine, and Quinidine, which are historically the most common quinoline-based drugs used to treat malaria, an infectious disease afflicting several hundred millions every year worldwide, mainly in tropical regions. Using UV-Visible spectrophotometry, the binding reaction was studied at $\mathrm{pH} 7.40$ in purely aqueous solution, and in aqueous solution containing $\mathrm{NaNO}_{3}$ at concentration of $0.1 \mathrm{M}$. Fitted titration curves obtained were in agreement with experimental data according to a formation scheme of 1:1 complex (1 FeTPPS $\mu$-oxo-dimer: 1 Antimalarial). Values of apparent binding constant $(\mathrm{K})$ obtained were between $4.3 \times 10^{3} \mathrm{M}^{-1}$ to $7.59 \times 10^{4} \mathrm{M}^{-1}$, demonstrating that FeTPPS and the antimalarials formed stable complexes. The stability of the complex decreased when $\mathrm{NaNO}_{3}$ was added to the solution. This ionic strength dependence was ascribed to electrostatic effects. Quinine and Chloroquine interacted with FeTPPS stronger than Quinidine did. Chloroquine showed the strongest affinity to FeTPPS. These findings revealed the influence of steric and stereochemical factors. Molecular electrostatic potentials (MEP) calculated with Hartree-Fock theory argue in favor of $\pi-\pi$ and electrostatic interactions between reaction partners as driving forces for the complex formation. In the case of FeTPPS: Chloro-
\end{abstract}


quine interaction, it is suggested that an intramolecular hydrogen bond is formed between phenyl $\mathrm{SO}_{3}^{-}$and quinuclidine $\mathrm{N}-\mathrm{H}^{+}$as additional force stabilizing the complex. Analysis of crystallographic data using the Cambridge Structural Database (CSD) gave evidence of the hydrogen bond formation between phenyl $\mathrm{SO}_{3}^{-}$and $\mathrm{N}-\mathrm{H}^{+}$groups in 370 structures.

\section{Keywords}

FeTPPS, Apparent Binding Constant (K), Molecular Electrostatic Potential (MEP), Cambridge Structural Database (CSD)

\section{Introduction}

Porphyrins and their derivatives are well-investigated molecules because of numerous potential applications from molecular electronics, over sensors and information storage elements, to medical agents [1] [2]. Ferric porphyrins seem to play an important role as receptor of an enormous number of ligands [3] [4] [5] [6] [7]. Iron(III)-5,10,15,20-tetrakis(4-sulfonatophenyl) porphyrin (FeTPPS), widely used in medicine to attenuate neurological damages, but also to treat the retinopathy of prematurity and for reanimation [8], is a synthetic derivative of the natural Iron(III)-protoporphyrin IX (FePPIX) (Figure 1).

FePPIX has been suggested as drug target of quinoline-based antimalarials [4] [9] [10] [11] [12] [13]. FePPIX is the oxidized form of heme released by the malarial parasite during the blood stage. The parasite digests hemoglobin in infected erythrocytes to recuperate the amino acids it needs. Detoxification of free heme into the acidic digestive vacuole is achieved by the formation of a polymer well known as hemozoin ( $\beta$-hematin) or malarial pigment [4] [14]. The interaction of quinoline antimalarial with FePPIX plays the important role of bringing

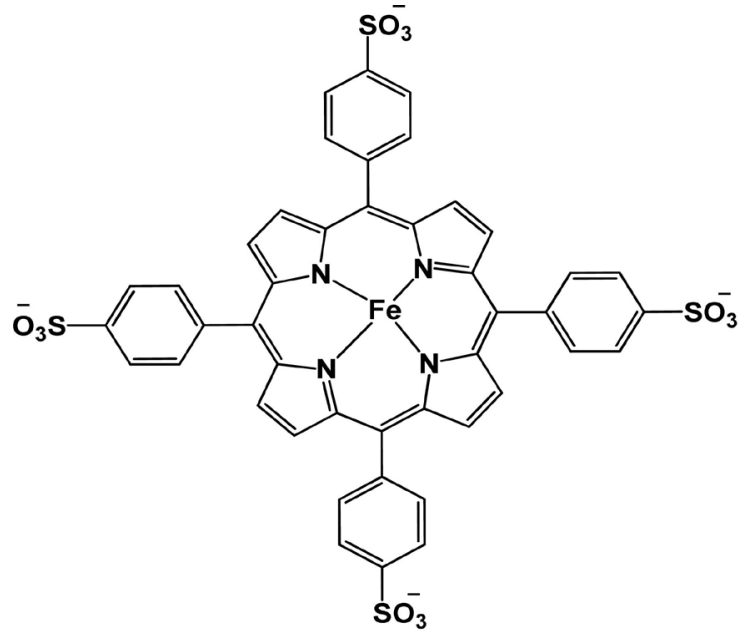

(a)

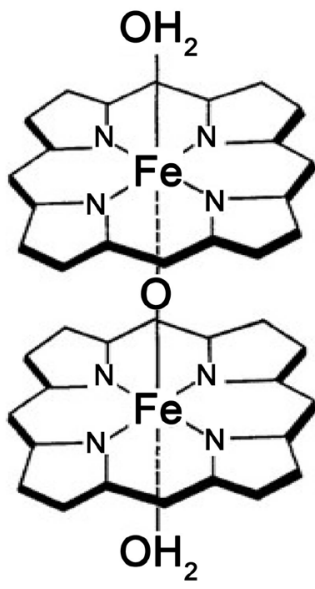

(b)

Figure 1. Structures of Iron(III)-5,10,15,20-tetraphenyl porphyrin sulfonic acid, Monomer (a) and $\mu$-oxo-Dimer (b). 


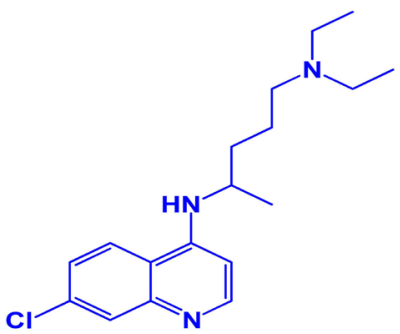

(a)

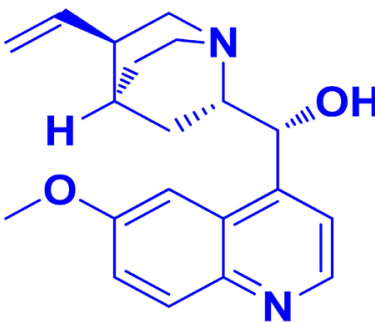

(b)<smiles>C=C[C@H]1CN2CC[C@H]1[C@H]([C@H](O)c1ccnc3ccc(OC)cc13)C2</smiles>

(c)

Figure 2. Structures of Chloroquine (a), Quinine (b) and Quinidine (c).

back the porphyrin into solution in order to block FePPIX unities, and to prevent the formation of hemozoin. The binding of FePPIX and its derivate Iron(III)-deuteroporphyrin IX (FeDPIX) to quinoline-based antimalarials Chloroquine, Quinine and Quinidine (Figure 2) have been demonstrated in vitro using mixtures of water with ethylene glycol, propylene glycol and DMSO [4] [11] [12] [15] [16] [17] [18]. It has been shown that the interaction depends on steric, stereochemical and electrostatic effects. Quinine is a carbinol-4 quinoline, originally derived from the bark of the cinchona tree. Quinidine is a stereoisomer of Quinine. Chloroquine is a 4-aminoquinoline long used in the malaria prevention and treatment, as it was cheap and widely available, before the most dangerous malarial parasite Plasmodium falciparum started to develop resistance to it.

It has been suggested that the most important driving forces for the formation of the complex are $\pi-\pi$ and hydrophobic interactions between the porphyrin ring and quinoline ring. The coordination of the iron center of Ferri-porphyrin by the alcohol/alkoxy functionality and an intramolecular hydrogen bond formed between the protonated quaternary quinuclidine nitrogen atom of a drug molecule and the negatively charged propionate side chain of the Ferri-porphyrin have been also mentioned as additional forces stabilizing the complex [12] [15] [19] [20]. Growing resistance of the Plasmodium to the quinoline antimalarials spurred the development of a new antimalarial pharmacological approach based on designing new molecules [21] [22]. A new antimalarial chemotherapy has been reported based on choline analogues with novel mechanisms of action [7] [23]. The authors reported that these drugs are "dual molecules", structurally unrelated to existing antimalarial agents, acting through two mechanisms: they interact with the plasmodial phospholipid metabolism and also with the malarial FePPIX polymer. However, quantitative studies of the interaction of the iron (III) porphyrin FePPIX in pure aqueous solution, the physiological medium, are hampered by the tendency of FePPIX to form aggregates considerably larger than dimers. In weakly acid and neutral solutions of FePPIX, a stable state cannot be achieved probably due to colloidal precipitation leading to artefacts in quantitative investigations [4] [7] [11] [15] [20] [24]. FeTPPS is sufficiently soluble in aqueous solution in a wide $\mathrm{pH}$ range due to four very strong acid groups $\left(\mathrm{SO}_{3} \mathrm{H}\right)$ compared to two weak acid groups $\left(-\mathrm{CH}_{2} \mathrm{CH}_{2} \mathrm{CO}_{2} \mathrm{H}\right)$ of FePPIX. Dimerization of FeTPPS into $\mu$-oxo-Dimer (O-FeTPPS ${ }_{2}$ ) can also be well controlled un- 
der experimental conditions in aqueous solution [3] [25] [26]. In this study, we report the results of the interaction of the iron porphyrin FeTPPS with Chloroquine, Quinine and Quinidine in pure aqueous solution and in aqueous solution containing $\mathrm{NaNO}_{3}$. The main goal is to explore the use of FeTPPS as ferric porpohryin model for the natural FePPIX for binding reactions in aqueous solution, the biological medium. FeTPPS has been considered as a non-physiological metalloporphyrin model for FePPIX. Gibbs E. et al. [27] investigated the interaction of Hemopoxin with FeTPPS used as model for FePPIX, which is the presumed target of the serum protein in blood stream. The authors demonstrated that hemopoxin is capable of binding with either Monomers or $\mu$-oxo-Dimers of FeTPPS. Complexes of FeTPPS with Nitric Oxide and Per-O-methylated-Cyclodextrin have also been used as primary models for FePPIX in ferrihemoproteins [5] [6].

\section{Experimental Section}

\subsection{Chemicals}

FeTPPS acid chloride, Chloroquine diphosphate and Quinidine, and Quinine were purchased from Frontier Scientific, Fluka (PA) and Merck (PA), respectively. Tris(hydroxymethyl) aminomethane (TRIS) was from Sigma Aldrich (PA). Stock solutions of FeTPPS and antimalarials were prepared in MilliQ-water (MQ-water) and buffered with TRIS. All static measurements were carried out in solutions containing $0.01 \mathrm{M}$ buffer. The $\mathrm{pH}$ values were measured with a glass electrode, which was soaked and kept in aqueous solution of $\mathrm{KCl}$ (3 $\mathrm{M})$ and was calibrated with aqueous standard buffers. A series of titration solutions at $\mathrm{pH} 7.40$ were prepared as previously described [4] [28] in which the concentrations of FeTPPS $\mu$-oxo dimer (D), TRIS and $\mathrm{NaNO}_{3}$ were held constant, at $5 \times 10^{-6} \mathrm{M}, 0.01 \mathrm{M}$ and 0 or $0.1 \mathrm{M}$, respectively, while the concentrations of the antimalarial ligand (L) were varied from 0 to $1.5 \mathrm{M}$.

\subsection{UV-Visible Spectrophotometric Study}

Experimental titration curves were carried out with a Perkin Elmer Lambda 40 UV-Visible spectrophotometer. Fitted curves were performed using a nonlinear least-squares regression based on the scheme describing the formation of a 1:1 complex (Scheme 1) according to the equation (Scheme 2) previously reported by Yav Gushimana et al. [3].

\subsection{Computational Study}

In addition to the experimental studies, a computational study was performed to

$$
\mathrm{D}+\mathrm{A} \stackrel{\mathrm{K}}{\rightleftharpoons} \mathrm{DA}
$$

Scheme 1. Model of Binding reaction of $\mu$-oxo-FeTPPS Dimer (D) with antimalarial ligand as ligand (A). $K$ is the binding constant related to activities of reaction partners. Thus, $K$ is depending on ionic strength. For diluted solutions, $\mathrm{K}$ is an apparent binding constant related to concentrations: $K=\frac{\bar{C}_{D A}}{\bar{C}_{A} \bar{C}_{D}}$. 


$$
\frac{E}{d}=C_{D}^{o} \varepsilon_{D}+\frac{1}{2}\left(\varepsilon_{D A}-\varepsilon_{D}\right)\left\{C_{D}^{o}+C_{A}^{o}+\frac{1}{K}-\sqrt{\left(C_{D}^{o}+C_{A}^{o}+\frac{1}{K}\right)^{2}-4 C_{D}^{o} C_{A}^{o}}\right\}
$$

Scheme 2. Nonlinear least-squares regression equation for the formation of 1:1 complex assuming that $\varepsilon_{A} \cong 0$ at wavelength of titration [3], and consequently $E=\varepsilon_{D} \bar{C}_{D}+\varepsilon_{D A} \bar{C}_{D A}$ [3]. $K, C, E, \varepsilon$ and $d$ represent the apparent binding constant, the concentration, the extinction, the molar absorption coefficient and the optical path, respectively; $\mathrm{C}^{\circ}$ is the initial total concentration and $E^{o}=d \varepsilon C^{o}$.

calculate molecular electrostatic potentials (MEP) based on the Hartree-Fock theory at basis sets 6 - $31 \mathrm{G}(\mathrm{d})$ and 3 - $21 \mathrm{G}$ implemented in GAUSSIAN09 [29]. The value of 0.1 a.u. was used for the isopotential.

\subsection{CSD Analysis}

The Cambridge Structural Database (CSD) Version 5.38 [November 2016] with a total of 843,799 structural entries was also used to explore the ability of phenyl $\mathrm{SO}_{3}^{-}$and protonated nitrogen to form hydrogen bond. We used the CSD system program ConQuest program for substructure searches and the location of non-bonded interactions [30] with the following secondary search criteria: atomic coordinates present in the entry and error-free after CSD evaluation; no disorder in the crystal structure; no polymeric (catena) bonding; no powder studies; crystallographic R-factor $\leq 0.10$; only organic structures (according to standard CSD definitions). The CSD System program Mercury [31] [32] was used for 3D structure visualizations.

\section{Results and Discussion}

\subsection{UV-Visible Spectrophotometry}

The Figure 3 depicts the absorption of FeTPPS and the antimalarial-based drugs between $600 \mathrm{~nm}$ to $350 \mathrm{~nm}$. As it is shown, given that the results were the same for the three antimalarial-based drugs, only Chloroquine is plotted.

We can see that (Figure 3) no absorption of quinoline-based antimalarials was observed in the visible region as illustrated with Chloroquine, whereas the spectrum of FeTPPS has a marked peak in the Soret Band around $413 \mathrm{~nm}$ and a small peak around $565 \mathrm{~nm}$ (Figure 3 ). These peaks correspond very well to those at $415 \mathrm{~nm}$ and $565 \mathrm{~nm}$, respectively, previously reported for $\mu$-oxo-Dimer of FeTPPPS [25]. And the variation of Extinction of FeTPPS at $410 \mathrm{~nm}$ in pure aqueous solution at $\mathrm{pH} 7.40$ versus concentration is plotted in Figure 4.

It can be seen that the absorption increases linearly obeying Beer's Law. This behavior demonstrates that only one species predominates in solution under the experimental conditions. Fitting of the molar absorption coefficient by the least-squares regression provides a value of $(1.59 \pm 0.02) \times 10^{5} \mathrm{M}^{-1} \cdot \mathrm{cm}^{-1}$, which is in good agreement with the value of $1.15 \times 10^{5} \mathrm{M}^{-1} \cdot \mathrm{cm}^{-1}$ previously reported for the absorption of FeTPPS $\mu$-oxo-Dimer [25]. Figure 5 shows titration of FeTPPS with Quinidine, which illustrates typical spectral changes in the Soret band of FeTPPS when the ferriporphyrin was titrated with antimalarial drug. 


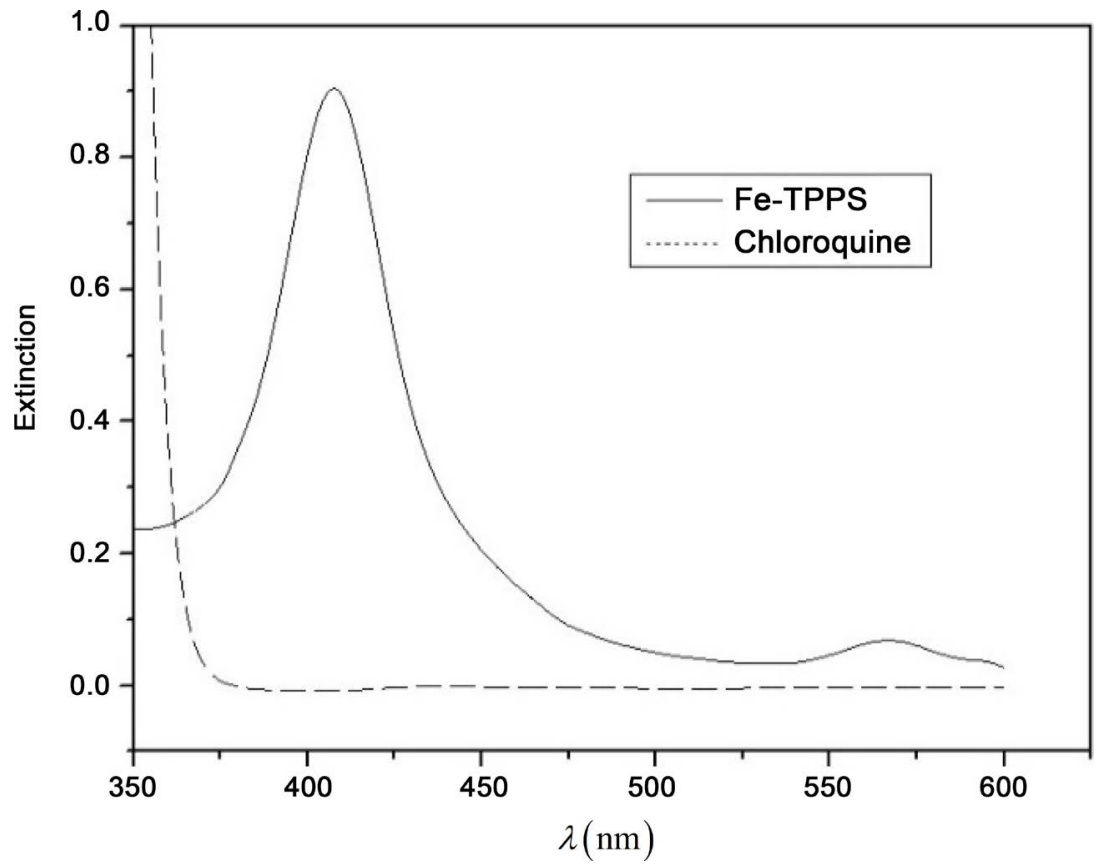

Figure 3. Absorption of FeTPPS and chloroquine between 350 to $600 \mathrm{~nm}$ at $\mathrm{pH} 7.4025^{\circ} \mathrm{C}$ and $\mathrm{NaNO}_{3} 0.1 \mathrm{M}$.

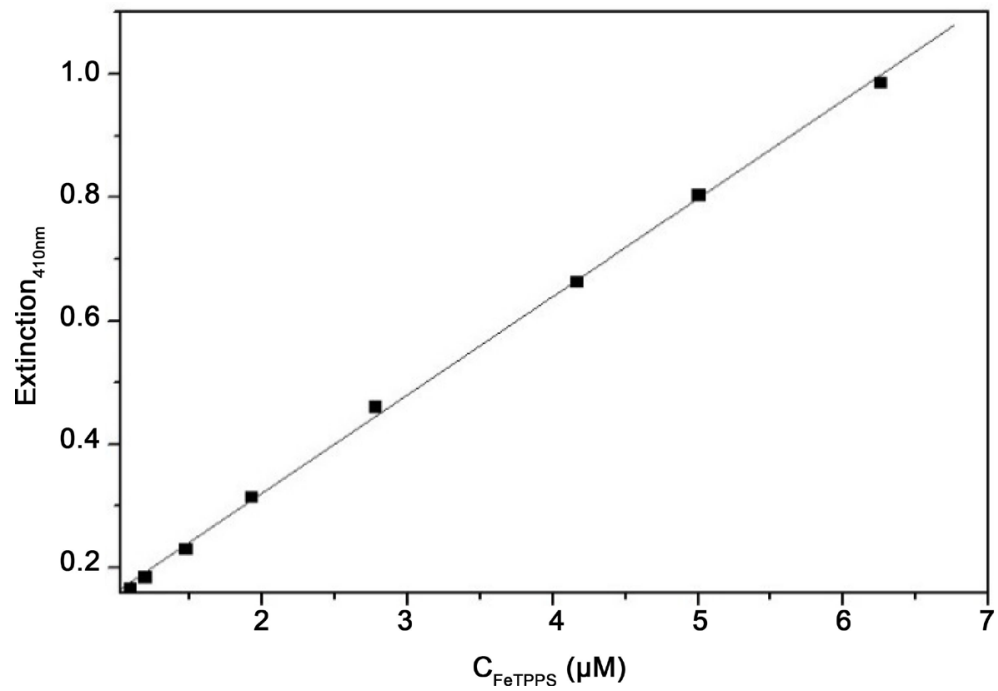

Figure 4. Absorption of FeTPPS increased linearly $\left(\mathrm{R}^{2}=0.99953\right.$ and $\left.\mathrm{SD}=0.01027\right)$ with the concentration of the porphyrin at $410 \mathrm{~nm}, \mathrm{pH} 7.40,25^{\circ} \mathrm{C}$ and $\mathrm{NaNO}_{3} 0.1 \mathrm{M}$.

Figure 5 reveals typical spectral changes induced by the addition of the antimalarial ligand in the aqueous solution of FeTPPS. The peaks of FeTPPS around $413 \mathrm{~nm}$ and $565 \mathrm{~nm}$ were still observed, but somewhat shifted and markedly damped with the increasing of ligand concentration. As illustrated in Figure 3, with the wavelength range ( $350 \mathrm{~nm}-600 \mathrm{~nm}$ ), only FeTPPS absorbs. Thus, any change of the peaks of FeTPPS by adding an amount of antimalarial-based drugs is the result of interaction. The variation in extinction is caused by the interaction of the FeTPPS $\mu$-oxo-Dimer with the antimalarial. Indeed, Also, there are two isosbestic points around $370 \mathrm{~nm}$ and $430 \mathrm{~nm}$, respectively, suggesting the 
complex formation [4] [28]. Mavakala et al. showed Chloroquine and Quinidine as the quinoline containing antimalarials with the strongest affinity to FePPIX [28]. They also argued that the affinity of the antimalarials depends on ionic strength and stereochemical factors. Figure 6 illustrates the experimental titration curves of FeTPPS with antimalarial drugs.

The shape of titration curves reveals that the absorbance of the $\mu$-oxo-Dimer decreases steeply and becomes relatively steady with the increase of the ligands as expected [4] [15] [28] [33] [34]. The complexation parameters were determined by plotting the titration curves of FeTPPS with antimalarial drugs according to the nonlinear least-squares regression equation (Scheme 2). Results (Figure 6) are in good agreement with curves fitted according to the formation

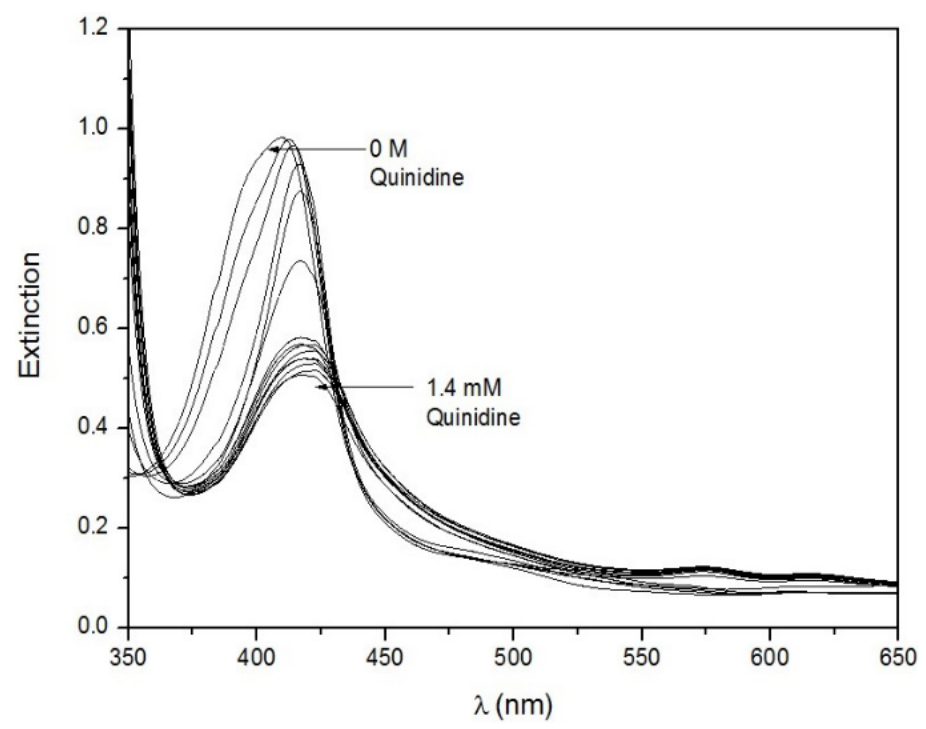

Figure 5. Spectral changes in the Soret Band when FeTPPS is titrated with increasing concentration of Quinidine in pure aqueous solution at $\mathrm{pH} 7.40$ without $\mathrm{NaNO}_{3}$.

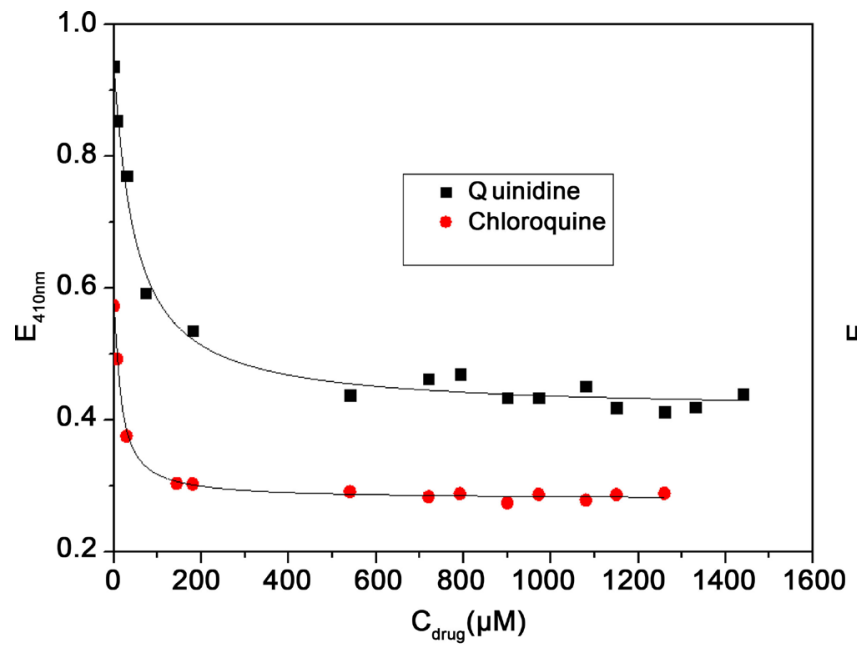

(a)

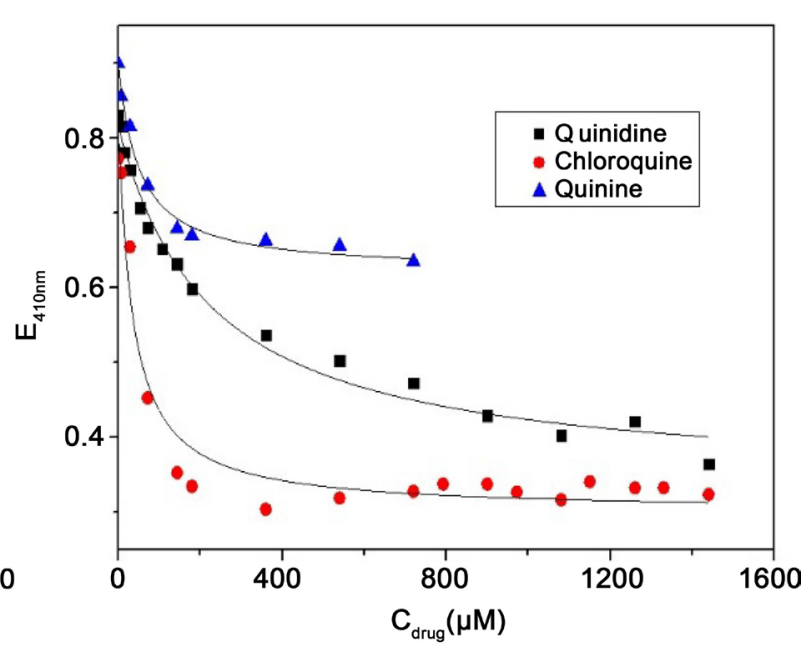

(b)

Figure 6. Spectrophotometric titration of FeTPPS at pH 7.40 (TRIS buffer) with (a) chloroquine and quinidine in aqueous solution without $\mathrm{NaNO}_{3}$ (ionic strength $\approx 0$ ) and $(b)$ chloroquine, quinidine and quinine at $0.1 \mathrm{M} \mathrm{NaNO}_{3}$ (ionic strength $\approx$ $0.1 \mathrm{M})$. 
Table 1. Apparent binding constants $(\mathrm{K})$ obtained from spectrophotometric titration in pure aqueous solution at $\mathrm{pH} 7.40,25^{\circ} \mathrm{C}$ in pure aqueous solution and in solution containing $\mathrm{NaNO}_{3}$.

\begin{tabular}{cccc}
\hline & \multicolumn{3}{c}{$\mathrm{K}\left(10^{4} \mathrm{M}^{-1}\right)$} \\
\cline { 2 - 4 } & Fe-TPPS-Chloroquine & Fe-TPPS-Quinidine & Fe-TPPS-Quinine \\
\hline 0.1 & $2.92 \pm 0.74$ & $0.43 \pm 0.08$ & $1.46 \pm 0.58$ \\
0.0 & $7.59 \pm 0.62$ & $2.14 \pm 0.31$ & - \\
\hline
\end{tabular}

of 1:1 complex (one FeTPPS $\mu$-oxo-Dimer: one antimalarial) described by the equation (Scheme 2). The values of the molar absorption coefficient at $410 \mathrm{~nm}$ obtained from the fitted curves were $(1.62 \pm 0.06) \times 10^{5} \mathrm{M}^{-1} \cdot \mathrm{cm}^{-1}$ and $(1.64 \pm$ $0.03) \times 10^{5} \mathrm{M}^{-1} \cdot \mathrm{cm}^{-1}$ in pure aqueous solution, that is, at $0 \mathrm{M} \mathrm{NaNO}_{3}$ and $0.1 \mathrm{M}$ $\mathrm{NaNO}_{3}$, respectively. It is noteworthy that these values are very close to the values fitted by the least-squares regression (Figure 4) and those reported by Everly et al. for FeTPPS $\mu$-oxo-Dimer [25]. The values of the apparent binding constant (K) calculated from fitted curves are listed in Table 1.

The values of the apparent binding constant (Table 1) reveal that FeTPPS forms stable complexes with Chloroquine, Quinine and Quinidine in aqueous solution as well as FePPIX and its derivative FeDPPIX do in mixtures of water with organic solvents like glycol and DMSO. Values K of $(0.33 \pm 0.06) \times 10^{5} \mathrm{M}^{-1}$ and $(0.11 \pm 0.03) \times 10^{5} \mathrm{M}^{-1}$ have been obtained for the complex formation of FePPIX with Chloroquine and Quinine, respectively, in 50\% water-propylene glycol mixture at pH 7.40 [28] [34]. Kai F. et al. [13] reported constants of dissociation for the complex formed between Chloroquine and FePPIX $\mu$-oxo-dimer at pH 6.5 and pH 9 of $3.9 \times 10^{-6} \mathrm{M}^{-1}$ and $4.1 \times 10^{-6} \mathrm{M}^{-1}$, respectively, which correspond to $2.6 \times 10^{5} \mathrm{M}^{-1}$ and $2.4 \times 10^{5} \mathrm{M}^{-1}$ in terms of binding constant. FeTPPS has the strongest affinity to Chloroquine in comparison to Quinine and Quinidine under the same experimental conditions. The affinity of FeTPPS to Quinine and Chloroquine decreases in aqueous solution when $\mathrm{NaNO}_{3}$ is added. These findings are similar to those for the binding of FePPIX and its derivate FeDPIX to quinoline antimalarials [15] [28] [33] [34]. It can be assumed that similar forces are involved in the interaction of FePPIX, FeDPIX and FeTPPS with the quinoline-based antimalarials considering that these ferriporphyrins have similar molecular structures. The main forces driving the complexation, as suggested, are $\pi-\pi$ stacking between the quinoline ring and the porphyrin ring, hydrophobic interactions, and electrostatic interactions [4] [19] [20] [28] [33] [34] [35]. De Villiers et al. [20] demonstrated that additional forces providing further stability of complexes between ferriporphyrins and carbinol-4 quinoline drugs are the possible coordination of the iron (III) by the alcohol/alkoxy functionality and a hydrogen bond formed between the protonated quinuclidine nitrogen atom and the propionate side chain. The strong affinity of Chloroquine to ferriporphyrins suggests that the complex is stabilized by the flexible aliphatic side-chain of Chloroquine, which is less crowded than the stiff quinuclidine group of Quinine and Quinidine [4] [20] [28]. The decrease of the FeTPPS affin- 
ity to Quinine and Chloroquine by addition of $\mathrm{NaNO}_{3}$ illustrates the dependence of the complex stability on ionic strength. The influence of ionic strength on the complex stability was also found by investigations in polar mixtures of water with ethylene-or propylene glycol [15] [28] [34]. However, no effects of ionic strength, which is characteristic of electrostatic interactions, have been observed in mixtures of water and DMSO probably due the weak polarity of the medium [18]. One could attribute the decrease of affinity to the influence of the ionic strength on the formation of FeTPPS $\mu$-oxo-Dimer. However, no major spectral change of FeTPPS absorption is observed in aqueous solution containing $\mathrm{NaNO}_{3}$ compared to the absorption in solution without $\mathrm{NaNO}_{3}$ (Figure 3 and Figure 5). Moreover, the values of the molar absorption coefficient fitted from titration are consistent with the value of the molar absorption coefficient of the FeTPPS $\mu$-oxo-Dimer reported by Everly et al. [25]. In aqueous solution at $\mathrm{pH}$ value of 7.40 , the acid phenylsulfonic group of FeTPPS is dissociated in anionic form and $\mathrm{H}^{+}$as the value of the dissociation constant $\mathrm{pKa}$ is 4.8 [25]. Investigations on the acid dissociation of protonated nitrogen atoms of quinoline antimalarials in aqueous solution provided two apparent constants, $\mathrm{pKa}_{1}$ and $\mathrm{pKa}_{2}$, [36] [37]. The authors found, respectively, $\mathrm{pKa}_{1}$ and $\mathrm{pKa}_{2}$ values of 8.08 and 10.16 for Chloroquine, 3.67 and 7.95 for Quinine and 3.50 and 7.81 for Quinidine. According to these $\mathrm{pKa} 1$ and $\mathrm{pKa}_{2}$ values, two nitrogen atoms of Chloroquine are protonated and only, one nitrogen atom $\left(\mathrm{pKa}_{2}\right)$ of Quinine and Quinidine is protonated according to values of $\mathrm{pKa}_{2}$ at $\mathrm{pH}$ 7.40. Thus, the observation that the addition of $\mathrm{NaNO}_{3}$ at high concentration in solution decreases the electrostatic interactions can be ascribed to shielding effects of $\mathrm{Na}^{+}$and $\mathrm{NO}_{3}^{-}$counterions on interacting charged groups in FeTPPS and antimalarial molecules [15] [28] [33]. In comparison to FePPIX and FeDPIX, two additional negative groups are provided to FeTPPS by phenylsulfonate side chains. However, no enhancement of electrostatic interactions and, consequently, no increased affinity of FeTPPS to antilamarial drugs is observed as expected. Contrary, $\mathrm{K}$ values of FeTPPS complexes are lower than those of FePPIX and FeDPIX complexes. This behavior demonstrates the main role played by steric effects on complex stability.

\subsection{Molecular Electrostatic Potentials}

The calculation of molecular electrostatic potential surfaces revealed that there are regions of negative charges and positive charges in the ferriporphyrins and the antimalarial molecule as expected. Marked negative charges (in red) are around the carboxylic groups of propionate side chains of FePPIX and sulfonic groups of sulfonate side chains of FeTPPS, but also around oxygen and nitrogen atoms of antimalarials (Figure 7).

These charged sites are probably responsible for electrostatic interactions between FeTPPS and antimalarial drugs enhanced in aqueous solution. However, Figure 3 also shows that the steric mesophenylsulfonic groups of FeTPPS are symmetrically disposed, all orthogonal to the porphyrin plane. Thus, electrostat- 


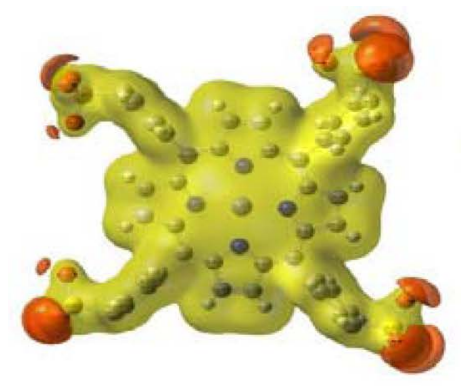

(a)

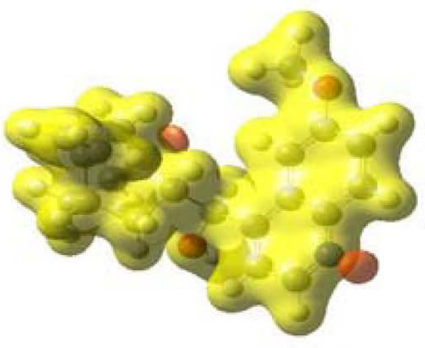

(b)

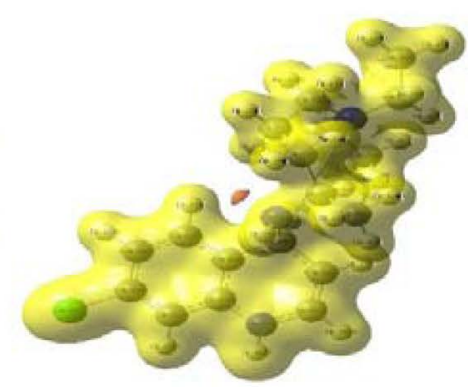

(c)

Figure 7. (a) MEP of FeTPPS at HF/3-21G(d), (b) MEP of Quinine at HF/6-31G(d), (c) MEP of Chloroquine at $\mathrm{HF} / 6-31 \mathrm{G}(\mathrm{d})$.

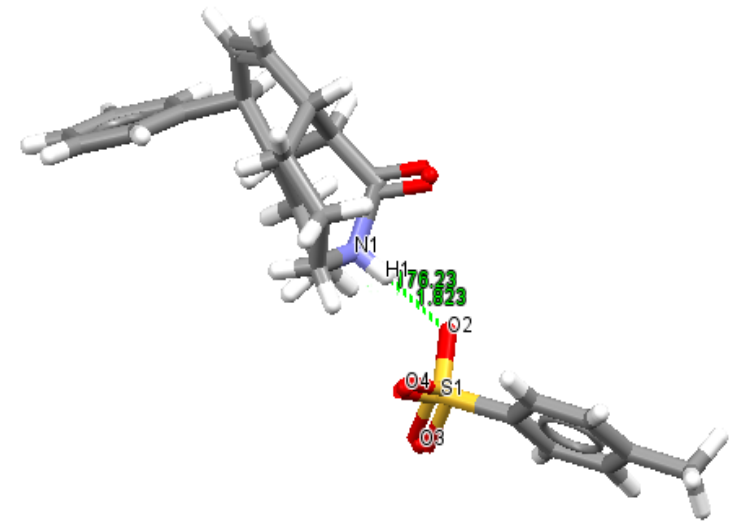

Figure 8. $\mathrm{C}(\mathrm{T} 3)-\mathrm{SO}_{3}^{-} \ldots \mathrm{H}-\mathrm{N}^{+}$Hydrogen bonding in CSD.

ic interactions as well as the $\pi-\pi$ stacking between the quinoline ring of antimalarials and the porphyrin ring of FeTPPS can be hampered by steric effects.

\subsection{CSD Analysis}

The complete CSD (all entries, with no secondary filters applied) contained $17,755 \mathrm{SO}_{3}^{-}$compounds of which 5924 (33.4\%) were organic and 11,831 (66.6\%), metal-organic complexes. When the secondary search criteria of Section 2.3 were applied, the total falls to 9112 structures of which 3848 (42.2\%) were organic and $5264(57.8 \%)$, metal-organic. Searches of organo-sulfonate compounds and, especially, on those compounds featuring mono-coordinate $\mathrm{SO}_{3}^{-}$atoms in $\mathrm{X}-\mathrm{SO}_{3}^{-}$bonds revealed 3843 structures containing $\mathrm{X}-\mathrm{SO}_{3}^{-}$ bonding in the CSD (a further 5 structures have $\mathrm{X}=\mathrm{SO}_{3}^{-}$subset). In the $\mathrm{X}-\mathrm{SO}_{3}^{-}$ subset, 3090 bonds (80.4\%) are $\mathrm{C}-\mathrm{SO}_{3}^{-}, 674$ (17.5\%) are $\mathrm{O}_{-} \mathrm{SO}_{3}^{-}$and the remaining 79 bonds (2.1\%) featured $\mathrm{X}=\mathrm{N}, \mathrm{P}, \mathrm{F}, \mathrm{S}$ or Se. An initial CSD survey showed that $2214 \mathrm{X}-\mathrm{SO}_{3}^{-}$compounds, with $\mathrm{X}$ assigned as any atom type, formed hydrogen bonds to strong $\mathrm{O}-\mathrm{H}$ or $\mathrm{N}-\mathrm{H}$ donors. The most abundant $\mathrm{X}$ type was a carbon atom with 1639 (74.0\%) compounds forming hydrogen bonds, while in 1117 compounds, the substituent was phenyl group. There were 821 compounds of this last group forming hydrogen bonds to $\mathrm{N}-\mathrm{H}$ donors, in which $370(45.1 \%)$ compounds formed hydrogen bonds to protonated $\mathrm{N}-\mathrm{H}^{+}$donors as illustrated in the Figure 8 (Refcode: ANEYOI). 
CSD searches provided many crystal structures forming relatively strong$\mathrm{SO}_{3}^{-} \ldots \mathrm{H}-\mathrm{N}^{+}$hydrogen bonds with median values of normalized lengths between 1.65 to $2.72 \AA$. This suggests that an additional hydrogen bond between the protonated quinuclidine nitrogen atom of Chloroquine and the negatively charged sulfonate side chain of FeTPPS molecule is also possible, which increases the complex stability.

\section{Conclusion}

The binding of FeTPPS to Chloroquine, Quinine and Quinidine in aqueous solution was investigated using UV-Visible spectrophotometry in conjunction with quantum mechanical calculations and (Cambridge Structural Database) CSD analysis. The results of the study show that FeTPPS can be used as ferric porphyrin model for the natural FePPIX for binding reactions in aqueous solution, the physiological medium. Indeed, spectrophotometric titration curves are well described by 1:1 binding scheme of FeTPPS dimer with the quinoline containing antimarials chloroquine, Quinine and quinidine. $\mathrm{K}$ values obtained support the formation of stable complexes. They also revealed that the stability of the complex depends not only on structural factors such as steric and stereoisomeric factors, but also on ionic strength. Thus, the complexation of FeTPPS with Chloroquine, Quinine, and Quinidine seems to be very similar to the complexation of FePPIX. In the light of this finding and results of ab initio calculations, it can be assumed that the main driving forces for the complexation of FeTPPS with quinoline-based antimalarials are also $\pi-\pi$ interactions more or less enhanced by structural factors and electrostatic effects. This work will be extended to the formation of complexes in acidic $\mathrm{pH}$ range aqueous solution as the biological activity of the drugs in vivo occurs in the acidic digestive vacuole of the malaria parasite.

\section{Acknowledgements}

The authors thank the British Council/DElPHE Programme (United Kingdom) for funding this study under Project 601 at University of Kinshasa. We are also grateful to the Dr. Colin Groom and the Cambridge Crystallographic Data Centre (CCDC) for providing CSD and Gaussian09. Pitchouna Kilunga is thankful to Professor Dr. Luc Van Meervelt for supporting the experimental part of the study at the Katholieke Universiteit Leuven in Belgium and to VLIR-UOS (Belgium) for funding the short research stay.

\section{Conflict of Interest}

The authors declare that this work has no conflict of interest with anyone.

\section{References}

[1] Sarayut, D., Andre, S., Martin, B. and Hendrik, U. (2007) Thermal and Electrical Properties of Porphyrin Derivatives and Their Relevance for Molecule Interferometry. The Journal of Chemical Physics, 126, Article ID: No. 164304. 
https://doi.org/10.1063/1.2721563

[2] Tsalu, P.V., et al. (2016) Distortions and Deformations of Metaled Meso-Substituted and Unsubstituted Porphyrins and Derivatives in Crystal Structures. Crystal Structure Theory and Applications, 5, 1-15. https://doi.org/10.4236/csta.2016.51001

[3] Fleischer, E.B. and Fine, DA. (1978) The Equilibria between Various Ligands and a Ferric Metalloporphyrin in Aqueous Solutions. Inorganica Chimica Acta, 29, 267271. https://doi.org/10.1016/S0020-1693(00)89659-0

[4] Gushimana, Z.Y., Doepner, B., Martinez-Hackert, E. and Ilgenfritz G. (1993) Kinetics of Quinine-Deuterohemin Binding. Biophysical Chemistry, 47, 153-162. https://doi.org/10.1016/0301-4622(93)85033-E

[5] Hoshino, M., Ozawa, K., Seki, H. and Ford, C. (1993) Photochemistry of Nitric Oxide Adducts of Water-Soluble Iron (III) Porphyrin and Ferrihemoproteins Studied by Nanosecond Laser Photolysis. Journal of the American Chemical Society, 115, 9568-9575. https://doi.org/10.1021/ja00074a023

[6] Koji, K., Hiroaki, K., Shigeto, T. and Akihisa, Y. (2004). Anion Binding to a Ferric Porphyrin Complexed with Per-O-methylated $\beta$-Cyclodextrin in Aqueous Solution. Journal of the American Chemical Society, 126, 15202-15210. https://doi.org/10.1021/ja045472i

[7] De Villiers, K.A. and Egan, T.J. (2009) Recent Advances in the Discovery of Haem-Targeting Drugs for Malaria and Schistosomiasis. Molecules, 14, 2868-2887. https://doi.org/10.3390/molecules14082868

[8] Kilunga, I.P. (2010) Crystallographic and UV-VIS Spectrophotometric Study of Four Potential Heterocyclic Ligands for Fe-TPPS. Master's Thesis, Katholieke Universiteit Leuven, Leuven.

[9] Chou, A.C., Chevli, R. and Fitch, C.D. (1980) Ferriprotoporphyrin IX Fulfills the Criteria for identification as the Chloroquine Receptor of Malaria Parasites. Biochemistry, 19, 1543-1549. https://doi.org/10.1021/bi00549a600

[10] Disashi, T., Gushimana, Z.Y., Mavungu, D.D., Musuyu, M. and Mpiana, P.T. (1997) Essais préliminaires d'évaluation de l'activité antipaludique in vitro du complexe ferriprotoporphyrine IX-Chloroquine sur le Plasmodium falciparum. Annales de I'Institut de Recherche en Sciences de Sante, 91, 22-35.

[11] Egan, T.J. and Marquis, H.M. (1999) The Role of Haem in the Activity of Chloroquine and Related Antimalarial Drugs. Coordination Chemistry Reviews, 190, 493517. https://doi.org/10.1016/S0010-8545(99)00112-5

[12] Mpiana, P.T. and Gushimana, Z.Y. (2000) Interaction Hémine-Antipaludéens: un pas vers la Solution du Problème du Milieu Réactionnel. Revue congolaise des sciences nucleaires, 16, 61-67.

[13] Kai, F.S., et al. (2008) Spin State of Chloroquine-Heme Complexes: Formation of Hemin Tetramer Adduct. The Open Spectroscopy Journal, 2, 10-18.

https://doi.org/10.2174/1874383800802010010

[14] Egan, T.J., Combrink, J.M., Egan, J., et al. (2002) Fate of Haem Iron in the Malaria Parasite Plasmodium Falciparum. Biochemical Journal, 365, 343-347.

https://doi.org/10.1042/bj20020793

[15] Gushimana, Z.Y., Mpiana, P.T. and Tshilanda, D.D. (1996) Etude de la Complexation de la Ferriprotoporphyrin IX avec la Quinine et la Chloroquine dans le Mélange eau-éthylèneglycol 50\%. Annales de la faculte des sciences, Universite de Kinshasa, 2, 145-155.

[16] Dorn, A., Vippagunta, S.R., Matile, H., et al. (1998) Comparison and Analysis of Several Ways to Promote Haematin (Haem) Polymerisation and Assessment of Its 
Initiation in Vitro. Biochemical Pharmacology, 55, 737-747. https://doi.org/10.1016/S0006-2952(97)00509-1

[17] Egan, T.J., Hunter, R., Kaschula, C.H., Marques, H.M., et al. (2000) Structure-Function Relationships in Aminoquinoléines: Effect of Amino and Chloro Groups on Quinoléine-Haematin Complexe Formation, Inhibition of Beta Haematin Formation and Antiplasmodial Activity. Journal of Medicinal Chemistry, 43, 283-291. https://doi.org/10.1021/jm9904371

[18] Egan, T.J. and Ncokazi, K. (2004) Effects of Solvent Composition and Ionic Strength on the Interaction of Quinoléine Antimalarials with Ferriprotoporphyrin IX. Journal of Inorganic Biochemistry, 98, 144-152.

https://doi.org/10.1016/j.jinorgbio.2003.09.007

[19] Moreau, S., Perly, B. and Biguet, J. (1982) Interaction de la Chloroquine avec la Ferriprotoporphyrine IX. Etude par Resonance Magnétique Nucléaire. Biochimie, 64, 1015-1025. https://doi.org/10.1016/S0300-9084(82)80382-9

[20] De Villiers, K.A., Gildenhuys, J. and Le Roex, T. (2012) Iron (III) Protoporphyrin IX Complexes of the Antimalarial Cinchona Alkaloids Quinine and Quinidine. ACS Chemical Biology, 7, 666-671. https://doi.org/10.1021/cb200528z

[21] Biot, C., Donatella, T., Isabelle, F., et al. (2005) Insights into the Mechanism of Action of Ferroquine. Relationship between Physicochemical Properties and Antiplasmodial Activity. Molecular Pharmaceutics, 2, 185-193.

https://doi.org/10.1021/mp0500061

[22] Michael, J.D., et al. (2005) Mapping Antimalarial Pharmacophores as a Useful Tool for the Rapid Discovery of Drugs Effective in Vivo: Design, Construction, Characterization and Pharmacology of Metaquine. Journal of Medicinal Chemistry, 48, 5423-5436. https://doi.org/10.1021/jm0408013

[23] Frolich, S., Schubert, C., Bienzle, U. and Siems, K.J. (2005) In Vitro Antiplasmodial Activity of Prenylated Chalcone Derivatives of Hops (Humulus Lupus) and Their Interaction with Haemin. Journal of Antimicrobial Chemotherapy, 55, 883-887. https://doi.org/10.1093/jac/dki099

[24] De Villiers, K.A., Marques, H.M. and Egan, T.J. (2008) The Crystal Structure of Halofantrine-Ferriprotoporphyrin IX and the Mechanism of Action of Arylmethanol Antimalarials. Journal of Inorganic Biochemistry, 102, 1660-1667.

https://doi.org/10.1016/j.jinorgbio.2008.04.001

[25] Everly, B., Joan, M., Srivastava, T.S. and Chatterjee, A. (1971) Thermodynamic and Kinetic Properties of an Iron-Porphyrin System. Journal of the American Chemical Society, 93, 3162-3167. https://doi.org/10.1021/ja00742a012

[26] Paul, F. and Ralph, G.W. (1989) Induced Dimerization of Tetrakis (P-Sulfonatophenyl) Porphine and Metalloderivatives by a Polyammonium Macrocycle [32]N8H88+. Journal of the American Chemical Society, 111, 4990-4992. https://doi.org/10.1021/ja00195a069

[27] Esther, G., William, R.S., William, T.M., et al. (1980) Reactions of Water-Soluble Metalloporphyrins with the Serum Protein, Hemopexin. Journal of the American Chemical Society, 102, 3939-3944. https://doi.org/10.1021/ja00531a042

[28] Mavakala, B.K., Nlandu, B.B., Mpiana, P.T., Gushimana, Z.Y. and Zhi-Wu, Y.V. (2003) Binding Reaction of Haemin with Chloroquine, Quinine and Quinidine in Water-Propyleneglycol Mixture. Chinese Journal of Chemistry, 21, 1022-1025.

[29] Frisch, M.J., et al. (2014) GAUSSIAN09. Gaussian Inc., Wallingford, CT.

[30] Bruno, I.J., et al. (2002) New Software for Searching the Cambridge Structural Da- 
tabase and Visualizing Crystal Structures. Acta Crystallographica Section B, 58, 389-397. https://doi.org/10.1107/S0108768102003324

[31] Macrae, C.F., et al. (2006) Mercury: Visualization and Analysis of Crystal Structures. Journal of Applied Crystallography, 39, 453-457.

https://doi.org/10.1107/S002188980600731X

[32] Macrae, C.F., et al. (2008) Mercury CSD 2.0-New Features for the Visualization and Investigation of Crystal Structures. Journal of Applied Crystallography, 41, 466-470. https://doi.org/10.1107/S0021889807067908

[33] Mpiana, P.T. (2003) Contribution à l'étude thermodynamique et cinétique de la complexation de la protohémine et de la deuterohémine avec les antipaludéens à noyau quinoléine. Thèse de doctorat, Université de Kinshasa.

[34] Mavakala, B.K. (2003) Interactions of Quinoléine and Artemisinin-Based Antimalarial Drugs with Hemin. Master's Thesis, Tsinghua University, Beijing.

[35] Egan, T.J., Mavuso, W.W., Ross, D.C. and Marques, H.M. (1997) Thermodynamic Factors Controlling the Interaction of Quinoléine Antimalarial Drugs with Ferriprotoporphyrin IX. Journal of Inorganic Biochemistry, 68, 137-145.

https://doi.org/10.1016/S0162-0134(97)00086-X

[36] Shalaeva, M., Kenseth, J., Lombardo, F. and Bastin, A. (2008) Measurement of Dissociation Constants (pKa Values) of Organic Compounds by Multiplexed Capillary Electrophoresis Using Aqueous and Cosolvent Buffers. Journal of Pharmaceutical Sciences, 7, 2581-2606. https://doi.org/10.1002/jps.21287

[37] Perrin, D.D. (1965) Dissociation Constants of Organic Bases in Aqueous Solution. Butterworths, London.

\section{Submit or recommend next manuscript to SCIRP and we will provide best} service for you:

Accepting pre-submission inquiries through Email, Facebook, LinkedIn, Twitter, etc. A wide selection of journals (inclusive of 9 subjects, more than 200 journals)

Providing 24-hour high-quality service

User-friendly online submission system

Fair and swift peer-review system

Efficient typesetting and proofreading procedure

Display of the result of downloads and visits, as well as the number of cited articles

Maximum dissemination of your research work

Submit your manuscript at: http://papersubmission.scirp.org/

Or contact csta@scirp.org 